This article was downloaded by: [Tilburg University]

On: 24 March 2011

Access details: Access Details: [subscription number 907217986]

Publisher Routledge

Informa Ltd Registered in England and Wales Registered Number: 1072954 Registered office: Mortimer House, 3741 Mortimer Street, London W1T 3JH, UK

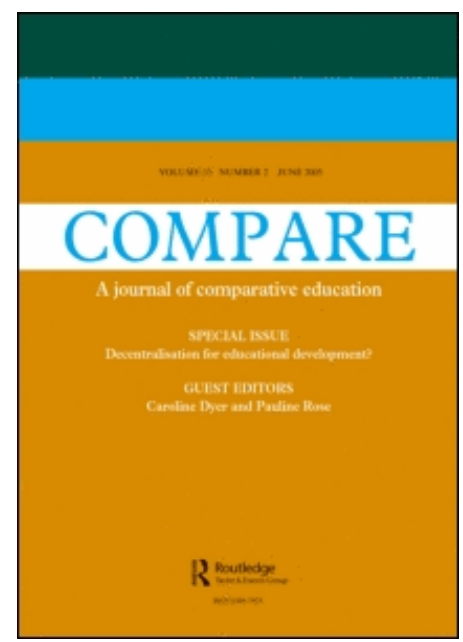

Compare: A Journal of Comparative and International Education

Publication details, including instructions for authors and subscription information:

http://www.informaworld.com/smpp/title $\sim$ content=t713410984

\title{
The old man and the letter: repertoires of literacy and languaging in a
} modern multiethnic Gambian village

Kasper Juffermans ${ }^{\text {a }}$

a Department of Culture Studies, Tilburg University, Tilburg, The Netherlands

Online publication date: 17 March 2011

To cite this Article Juffermans, Kasper(2011) 'The old man and the letter: repertoires of literacy and languaging in a modern multiethnic Gambian village', Compare: A Journal of Comparative and International Education, 41: 2, 165 - 179

To link to this Article: DOI: 10.1080/03057925.2011.547286

URL: http://dx.doi.org/10.1080/03057925.2011.547286

\section{PLEASE SCROLL DOWN FOR ARTICLE}

Full terms and conditions of use: http://www.informaworld.com/terms-and-conditions-of-access.pdf

This article may be used for research, teaching and private study purposes. Any substantial or systematic reproduction, re-distribution, re-selling, loan or sub-licensing, systematic supply or distribution in any form to anyone is expressly forbidden.

The publisher does not give any warranty express or implied or make any representation that the contents will be complete or accurate or up to date. The accuracy of any instructions, formulae and drug doses should be independently verified with primary sources. The publisher shall not be liable for any loss, actions, claims, proceedings, demand or costs or damages whatsoever or howsoever caused arising directly or indirectly in connection with or arising out of the use of this material. 


\title{
The old man and the letter: repertoires of literacy and languaging in a modern multiethnic Gambian village
}

\author{
Kasper Juffermans* \\ Department of Culture Studies, Tilburg University, Tilburg, The Netherlands
}

\begin{abstract}
Recent developments mark a 'human turn' in sociolinguistics, i.e., a move away from languages as linguistic systems used by people, toward language or languaging as a sociolinguistic system performed by people. This article inscribes itself in that tradition and offers a micro-ethnographic analysis of a literacy event in rural Gambia. The incident relates to a letter that was 'written' by an old illiterate villager in the process of arranging a family member's marriage. Although the event in itself is fairly insignificant and trivial, it is mobilised to gain an insight into the social and cultural organisation of literacy and languaging in this village. The old man's letter is a typical moment of 'grassroots literacy' and is not 'orthographic' but 'heterographic' (reflecting more than one prescriptive regime) and 'exographic' (drawing on imported normativity). Local languaging here is not the sum of the local languages (Mandinka plus Jola plus Fula plus English) but is a complexly regimented repertoire in which different functions of language are distributed differently across languages and individuals.
\end{abstract}

Keywords: ethnography; literacy; multilingualism; West Africa; languaging

\section{Language, languages, languaging}

According to Møller and Jørgensen (2009, 147), 'as human beings, we do not primarily use "a language", or "some languages", [but] we use language, linguistic features, and we do so to achieve our aims'. They therefore propose a shift in the attention of sociolinguistics away from languages as codes or linguistic systems, to 'languaging' and 'languagers'. Sociolinguistics would then no longer be the study of 'who speaks (or writes) what language (or what language variety) to whom, and when and to what end', as Fishman (1972) defined the field, but the study of who languages how and what is being languaged under particular circumstances in a particular place and time. The notion of 'languaging' has been part of the English lexicon at least since the seventeenth century (Joseph 2002). However, it has gained popularity only recently in studies of multilingualism (see also Jørgensen 2008, Pietikäinen et al. 2008; Shohamy 2006) and reflects 'a human turn' in sociolinguistics, i.e., a move away from languages (in plural) as linguistic systems that are used by people, toward language (in singular or as a verb) as a sociolinguistic system that is constructed and inhabited by people.

In this type of sociolinguistics (a sociolinguistics of language as opposed to a sociolinguistics of languages), the analysis revolves around human beings engaged in particular activities and situated in particular networks in time and space (Blommaert et al. 2005, Thorne and Lantolf 2007). This type of sociolinguistics is rooted in the

*E-mail: k.p.c.juffermans@uvt.nl 
ethnography of speech and literacy events (Bauman and Sherzer 1975; Baynham 2004; Hymes 1967; Street 2000) as well as in studies of code-switching (e.g., Gafaranga 2000; Swigart 1992). Such a sociolinguistics takes as starting point that 'languages are conceived and languaging is practiced' (Mignolo 1996, 181) and that languages are 'inventions', both in nomenclature as well as in their historical development (Makoni and Pennycook 2007). Multilingualism is thus understood not as the co-occurrence of multiple languages in a particular context, i.e., as multiple monolingualisms, but as 'polylingual' practice, i.e., languaging with 'whatever linguistic features are at [speakers'] disposal' (Møller and Jørgensen 2009, 146), or as a multilingualism that is 'truncated', i.e., with topic and domain specific competence in multiple language varieties (see Blommaert et al. 2005; Dyers 2008).

Thus, it should be safe to say that there is no such thing as full competence in a language or full literacy skills. What we speak, the composite of our lingual abilities or communicative skills, is a lapidary repertoire, a collection of linguistic features that are recognisable as features of a particular variety, style or way of speaking, rather than a sum of languages. When speaking, we only make use of certain features that are available to us, never of an entire language. There is nobody who speaks an entire language ('language' being defined here as the sum of all features that are recognisable as 'belonging' to a particular language) and there is certainly nobody who speaks two. Bilinguals, if we are to continue using this term, do not speak two languages, but they language, making use of features that may be recognised by themselves or others as 'belonging' to two different sets of features. What features we display in languaging and what features we prefer to hide, is determined by our individual histories of learning as well as by 'the whole aggregate of conditions under which any given community of speakers operates' (Vološinov 1986, 93).

Hymes' (1967; 1986) ethnography of speaking forms a more useful starting point than Fishman's question for sociolinguistic investigations of actual situations of languaging. In reality, speakers are always constrained by a variety of limitationssituational, interactional, biographical, social, structural. An ethnographic sociolinguistics is primarily concerned with these constraints and urges us to start by describing lived realities, i.e., real events with real people using real language, and not hypothetical groups or individuals in hypothetical situations doing hypothetical things. Such a descriptive ethnographic sociolinguistics promises a deeper understanding of the social, cultural and interactional foundations of languaging in practice.

Ethnography of speaking is part of a qualitative descriptive programme of sociolinguistics and linguistic anthropology that originated in the 1960s and 70s as a development of Jakobson's (1960) communication scheme and has influenced projects such as 'new literacy studies' (e.g., Street 1995) and 'linguistic ethnography' (e.g., Rampton et al. 2004). Part of its success is due to the fact that Hymes turned SPEAKING into a mnemonically convenient acronym with a contextual factor for every letter of the word: Situation-setting and scene, Participants-speaker, addressor hearer, and addressee, Ends-outcomes and goals, Act sequence-message form and content, Key, Instrumentalities-channel or medium, and forms of speech ('language'), Norms-of interaction and interpretation, and Genres. This model, however, should not be taken as an instant recipe that can routinely be applied to all sorts of communicative events; it should rather be treated as an imperative for descriptive holism. The idea is that if one describes all 16 contextual components or all eight letters of the SPEAKING-acronym in a more or less systematic way, then one's description of the communicative event should be fairly complete. 
What is interesting for our purposes here, is that in the ethnography of speaking there is no explicit reference to language or languages, but to forms of speech as part of ways of speaking. Communication, and not a particular language is at the centre of this model. What is important, is that speaking is not locked up in a particular language, but can spread out over multiple languages and idiomatic practices (Jacquemet 2005; Jørgensen 2008; Rampton 1995). With the ethnography of speaking (or of writing, Basso 1974) the focus of the linguist is not necessarily on a particular language at a particular time, but on a particular community of practice in which more than one medium and mode of communication (including what are usually called 'languages') are available and used at the same time.

Work in ethnographic sociolinguistics and new literacy studies has never been far removed from the concerns of discourse analysis (e.g., Blommaert 2005; Gee 1996). The typical division of labour between discourse analysis and ethnography is that discourse analysts occupy themselves with the products of communication (i.e., spoken or written texts) and ethnographers with the process or practice of speaking and writing (e.g., speech acts, encounters, literacy events). Ethnographers of literacy then can be expected to deal with moments of speaking or writing, with literacy events, while discourse analysts are more concerned with the artefacts of communication, with literacy products, with the things we call texts. There are, however, fruitful ways of blurring these distinctions, of analysing discourse ethnographically and of engaging with texts within a broader ethnographic project (see e.g., Blommaert 2008; Fabian 1990; Mbodj-Pouye 2009).

In this article, I will offer one such ethnography of literacy, focusing on a literacy event that I witnessed more or less accidentally, by 'surprise' as Willis and Trondman (2000) would say, during my fieldwork in rural Gambia. This event should be understood as an ethnographic 'rich point' (Agar 1995) or a 'key incident' (Kroon and Sturm 2000), i.e., a moment in which one witnesses an at first sight meaningless or mundane event that renders an increased understanding of the research subject. It is these rich points that are important to ethnographers, and much of anthropological literature consists of 'thick descriptions' (Geertz 1973) of these experienced micro-events.

The incident I am concerned with here dates from 2004 and relates to a letter that was 'written' (with help) by an old illiterate villager in the process of arranging the marriage of his stepson with a girl from the same village. The event itself is fairly ordinary, insignificant, trivial even, but can be mobilised to arrive at important insights into the social and cultural organisation of literacy and languaging in this particular village community and, by extension, Gambian society at large. The analysis presented here is a contextual analysis of the writing event that took place right in front of me, however without having been able to read the letter myself. By analysing the immediate and wider context surrounding this text, meaningful insight can be gained into literacy as a situated practice, even without the text itself at hand. This analysis should ideally be coupled with a textual analysis (e.g., as done in Juffermans 2009), however in an ethnographic sociolinguistics, the analyst has to resort to whatever is available. In ethnography, the type of analysis that may be pursued depends on the type of data available, rather than the other way around.

The descriptive aim of this article is to explore more intimate aspects of literacy and multilingual practice in one village community through a careful description of one communicative micro-event. This article is also an attempt to further destabilise the idea of language(s) as fixed and separate entities. Through an analysis of the letter writing event, I aim to show how the notions of languaging and repertoire are more 
useful than 'languages' or 'a language' in understanding how literacy works in a multilingual, postcolonial society such as The Gambia.

The remainder of the article is structured into three parts. I first outline the ethnographic context of the village as well as the ethno- and sociolinguistic backgrounds of the main persons involved in the discussion here. I then describe and analyse the letter writing event itself, making use of the above-mentioned terminology of ethnographic sociolinguistics. The article concludes with a discussion of the local sociolinguistic system of literacy and languaging.

\section{Ethnographic context}

The account of literacy in this article is situated in a modern multiethnic village in Foni (pronounce [foni]), in rural southwest Gambia. The village is referred to as a modern village because people have lived there for only three to four generations and because it is built around the structures of the modern state. The village stretches out on each side of a T-junction that is formed by the main south bank road and a secondary road going to a riverine village further north. The East-West axis is an important orientation to people of the village as they face East when they pray and head West when they travel to the city.

The village is referred to as a multiethnic village because no ethnic group forms an absolute majority, even though the village is located in an area that is historically dominated by Jolas, and also 'owned' by Jolas, i.e., the alkaloship (local political leadership) of the village remains in the lineage of the Jola founders of the village. In an ethnolinguistic survey carried out in July-August 2005 (with my colleague Vanantwerpen) among 248 villagers of all ages, representing roughly one third of the population, $33 \%$ responded by saying that they were Jola, 31.5\% Mandinka, 17.5\% Fula, 9\% Manjago and $6.5 \%$ Wolof. Furthermore, $10.5 \%$ of interviewees declared that they had been born into an ethnically mixed marriage, and $8.5 \%$ of married respondents reported that they were married to someone from a different ethnic group. With regard to the linguistic resources available to this rural population, there are the languages of the above and other ethnic groups, but also international languages such as English, French, Arabic and Portuguese Creole. There is a clear lingua franca in this village, as revealed in the high number $(95 \%)$ of respondents who declared that they were speakers of Mandinka. Multilingualism is the rule here, however, as Jola and Wolof are also spoken by more than half of the population surveyed (59 and 57\% respectively), and Fula by over a third (35\%). English was claimed to be understood by $43 \%$ of the respondents, Arabic by $14 \%$ and French by $9 \%$. It was not possible to get reliable answers on our questions regarding literacy, perhaps due to overdifferentiation in our questionnaire grid. It may be estimated, however, that about half of the young men in the village were literate to some extent in either English or Arabic and that this number would be somewhat lower for young women and middle-aged men. Very few elderly persons are likely to have been literate, either in English or in local languages. A good number of young and middle-aged women participated in the seasonally organised adult literacy classes. Although women of all ethnic groups took part, these classes were only available for Mandinka. In the linguistic landscape of the village there was little visible evidence of any language other than English.

I became acquainted with the wider sociolinguistic and cultural background of this village during several ethnographic fieldwork trips, which involved (participant) observation, informal conversations and the aforementioned survey. To further contextualise the literacy practices of the protagonists I now need to explain the material and 
communicative resources of the protagonists as well as how they relate to each other. The main agents featuring in the analysis of this article are all related to the Mandinka (Muslim) family that hosted me during my fieldwork there. My fieldwork consisted of various stays of differing length between 2004 and 2009, ranging from quasi-uninterrupted stays of several weeks in the beginning of the project to a few days toward the end of it.

I was introduced to this family and this village by Lamin, whom I had met three years earlier on vacation. Our initial encounter was an ordinary case of a fleeting tourist-host encounter characterised by all the economic and socio-political asymmetries defined by our relative positions in the world (Lawson and Jaworski 2007, 88), but developed into friendship. Although there remained important inequalities between us, this did not preclude engagement with each other on a basis of equality and reciprocity. In our correspondence during my first years at university as a student of African studies, two letters crossed each other at one point, one from him requesting assistance from me with the building of his house, and one from me requesting his help with finding a research locale, preferably in a rural setting, to do research for my master's thesis. Although we were not able to 'pay' each other in the same currency, we helped each other in whatever way we could and have, in the process of my repeated visits, first as a tourist, later as a researcher, learned a lot from each other and become close friends, even family in the associative sense of the word.

Lamin's family in the village consisted of his mother, his younger sister Fatou with three of her four children and another Lamin (nicknamed L), whose mother was Lamin and Fatou's elder sister (kotomaa). Lamin and Fatou's father, the second husband of their mother, had already passed away, making Lamin as only male descendent the owner of the compound (kordaa tiyoo). Lamin was roughly ten years older than me, being in his early to mid-thirties in 2004. At that time, family pressure was high for Lamin to get married and 'become responsible'. Lamin's mum was not Mandinka herself, but Fula. Her brother, Lamin's uncle, also lived in the village with his family. Thus, Lamin's cousins (mbarindinolu) were not Mandinka but Fula. Through a different branch, the family also had Jola consanguinity.

Lamin had attended the public lower basic school in his district and had been successful enough to be able to continue his education at secondary level, for which he had had to move to a larger town upcountry where he could stay with his uncle (mbariy). Upon completion of his education, his elder brother (kotomaa) Yusupha had arranged for Lamin to work as a seasonal security officer in the hotel where we met. When Lamin went for promotion and was hired for the entire year, he started building a new house on his father's land. The next, and more important step, was to get married. Still, Lamin led a life that he would characterise as 'not easy' or 'just managing'. In the beginning of his work in hotel security, Lamin had occupied a room with a cousin in Greater Serrekunda. He later moved to stay with his brother Yusupha who had acquired land and built a house elsewhere in urban Kombo. Lamin's job gave him a small monthly salary, most of which he spent on commuting to his work, on 'fish money' to his brother's wife, and supporting his family in the village.

The 'old man' mentioned in the title of this article, was called Ba-Abdoulie and was a stepfather to Lamin. Ba-Abdoulie was a Fula who had grown up in the town of Labé in central Guinea before coming to Foni in The Gambia as a young man. Having spent several decades in The Gambia without ever going back to Guinea, Ba-Abdoulie had fully integrated into Gambian rural society and was no longer considered an immigrant. Ba-Abdoulie was blessed in his old age with a younger wife and three 
young children. He had his compound on the other side of the road, just two minutes away from our compound. During my fieldwork, he frequently came to our compound to pass time and chat with us. He had great joy in teaching me words and phrases in Mandinka as well as in his native Fula.

Verbally, Lamin and Ba-Abdoulie were very articulate and highly multilingual. Although it is not straightforwardly possible to assess their language proficiency in such terms of the Common European Framework of Reference for Languages (Council of Europe 1996), it is clear that Ba-Abdoulie, for instance, was 'effectively proficient' in, or in fact 'mastered' several languages (Mandinka, Fula, Jola) and could draw upon resources from a variety of other languages in which he had a 'basic-level' or 'threshold' competence in(Wolof, Arabic) as well as elementary features of languages in which he would not recognise any true proficiency in (English, French). Although Ba-Abdoulie was highly multilingual in speaking, interacting and listening, as a typical product of his generation he had not received any formal, classroom-based education and remained illiterate (in any of the languages in repertoire) throughout his life. Ba-Abdoulie had, however, acquired the very basic skills to recognise and distinguish English from Arabic literacy.

\section{Writing in the village}

Let us now turn our attention to the letter writing event I mentioned in the beginning of this article. To start with a caveat, the only thing I have of that letter, or rather of the draft of that letter, is a snip of paper ripped out of an exercise book which only shows the words 'the' and 'will' (Figure 1). That is certainly not enough text for a

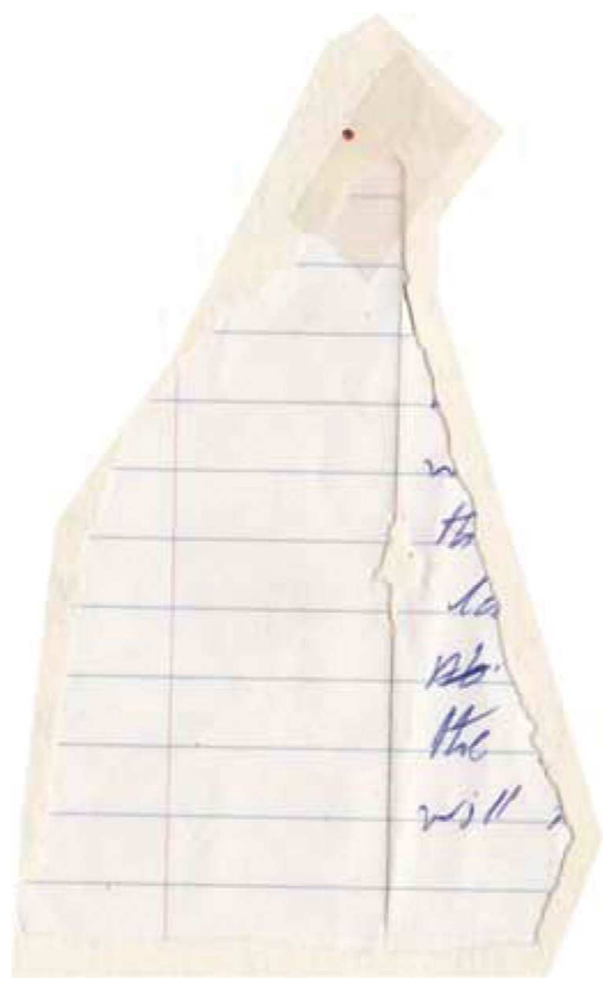

Figure 1. Snip of the letter. 
good discourse analysis. In this respect, Hymes writes that '[o]nly painstaking analysis of message form-how things are said-[...] can disclose the depth and adequacy of the elliptical art that is talk' (Hymes 1986, 60). In ethnography, however, one must make do with what one has got. Not having the letter itself constrains the analysis, but may a posteriori even be considered an advantage if we manage to turn the scarcity of available material into a strength. Although it would have been interesting to have had access to the contents of the letter, the text itself forms only a small part of the whole literacy event. There is so much surrounding the text that when all of that is taken into consideration, one does not necessarily need the text itself anymore to describe what is going on.

It was a typical hot afternoon in the village. I had returned from my observations in school and tried to make myself comfortable under the veranda with a wooden stool leaning against the wall of the house to make a few field notes. I had not been sitting for a long time when teenager Buba, whom I did not know that well, asked me for a pen and a piece of paper. A little while later, Ba-Abdoulie and Buba installed themselves within arm's reach of where I was sitting and started writing a letter together. I sensed that great 'data' was in the making, and decided not to go anywhere. Instead, I started noting down what I saw happening right in front of me, making a somewhat free use of the ethnography of speaking model as outlined above. In order to be as unintrusive as possible, no sound-recordings were made, but it was possible to take the photograph in Figure 2 without disturbing the situation too much. In the background, we could hear children playing and people chatting while brewing attaya 'green tea' and see chicken and goats passing by in search for something to eat.

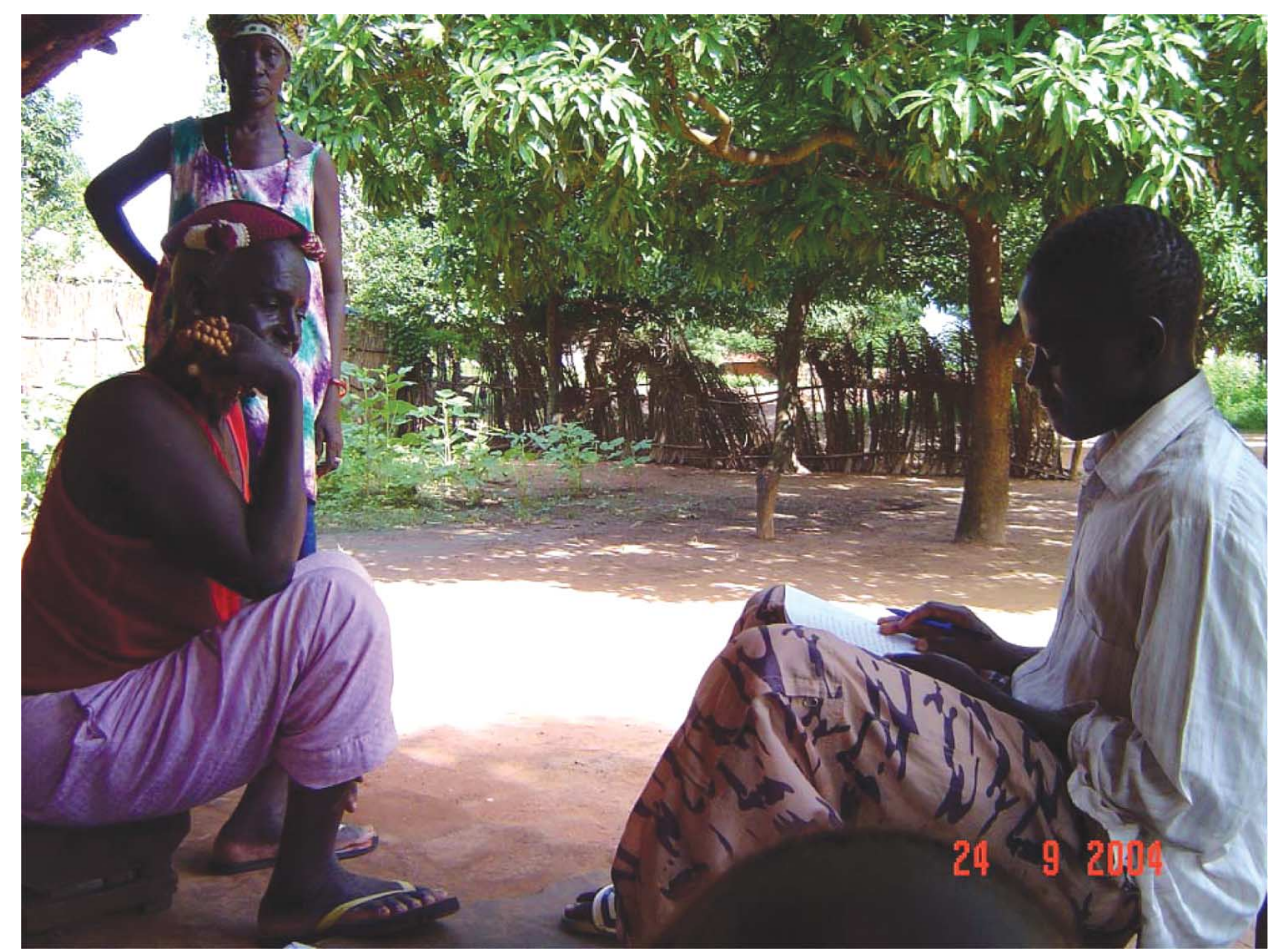

Figure 2. Photo of the letter writing event. 
The reason why Ba-Abdoulie needed to write this letter-certainly not a very common event in this setting, or in Ba-Abdoulie's life-was the following: Lamin was preparing to marry a girl from the same village, Isatou. In keeping with traditions, Lamin's family had to supply a dowry to the bride's family before the wedding could take place. Isatou's family wanted their house surfaced and had requested a number of bags of cement as well as the manpower to carry the work out. The manpower was no problem, however, the cement was. At the end of September, the situation between the two families was in such deadlock that Ba-Abdoulie had decided to intervene in the situation. He decided to request the assistance of Lamin's somewhat well-off elder brother Yusupha, and to make this request official by writing. Only Ba-Abdoulie had not learned to write. He therefore had to call for help from a literate member of his community, who would be willing to spare some time to help an old man. Ba-Abdoulie found this assistance in the person of Buba, a young man from a neighbouring family.

It is not immediately clear how many participants there were in this letter writing event. First of all there were the people who formed the core of the event, i.e., BaAbdoulie and Buba. And as is usually the case with letters, there is an addressee who is absent from the scene itself-Yusupha. Physically present on the scene and visible in the photo but claiming a less prominent role was Lamin's mother. She was not actively involved in writing the letter and could perhaps best be described as a concerned 'overhearer' or 'auditor', using the terminology of Bell's (1997) audience design. She would, from time to time, interrupt her household work to listen to how Ba-Abdoulie and Buba were writing the letter. Other overhearers were L, who was brewing attaya (strong green tea) a stone's throw away from where we were sitting, and the girls Kumba and Aja who came to seek my attention, with relatively little success this time.

My role was a bit ambiguous. Clearly, what I was doing was participant observation. I was sitting at arm's length of Ba-Abdoulie and Buba and I was the one who took the photo (accidentally also capturing my own knee). I was also a concerned onlooker, for different reasons, and was actively involved in the event in several ways: I was asked to supply the literacy materials (pen and paper) and later also to deliver the letter to Yusupha.

Not strictly participating in this letter writing event were Lamin and Isatou, who wanted to get married, and Isatou's family, who were imposing the burden of the dowry on Lamin's family. They were, however, the cause and raison d'être of this letter, and therefore also participants here. The different roles assumed in this event are depicted in a communication scheme in Figure 3.

Although I was able to photograph the event and participate as an observer, the letter itself was kept away from my inquisitive gaze and quickly put into an envelope. The draft was shredded in pieces and thrown away. As an inexperienced, compliant ethnographer, I did not pursue this any further. Opening the letter, or not delivering it, I thought, would be an improper way of gathering ethnographic data. And when I delivered the letter in Yusupha's compound, I only found Lamin there, who also did not think it appropriate to open the letter before his brother came back from work. I thereby lost the opportunity to get access to the letter itself.

From the two times the letter was read aloud, I wrote down in my field notes that the letter was basically a brief explanation of the problem that was most likely already known to Yusupha anyway, as well as a formal request for support to help successfully arrange this marriage. As the request came from a fatherly person, and in the 


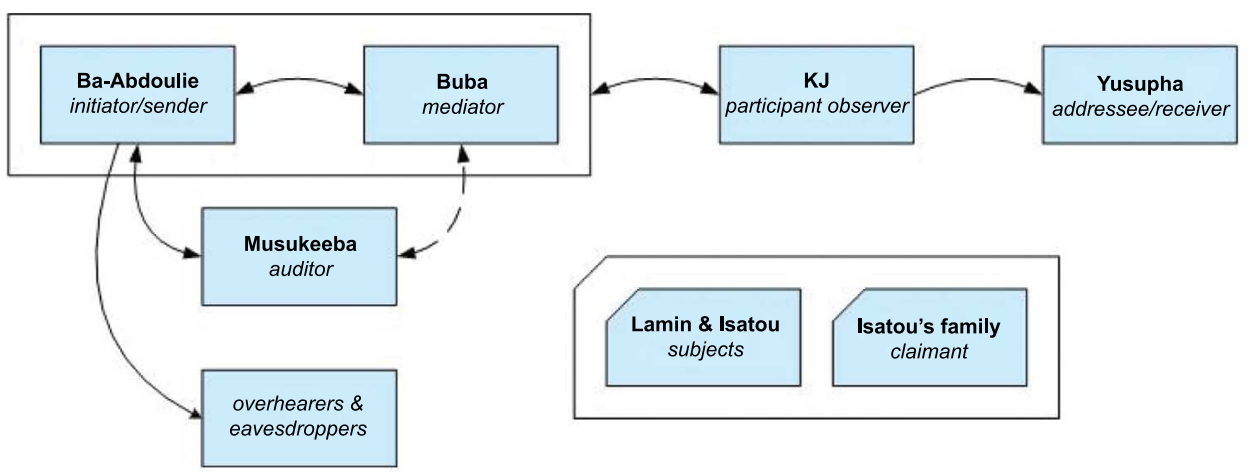

Figure 3. Participants of the letter writing event in a communication scheme.

form of a letter, the request could not be taken lightly, and refusing assistance when in a position to do so, would be disrespectful. With high stakes in play, the letter was taken very seriously. It took a whole afternoon to write it: the letter was first drafted and then neatly copied out on a new sheet of paper. As an indication of time, three rounds of attaya were brought to us while this letter was being written. The interval between each brew was about one hour. Further, a lot of formal and polite figures of speech were used in the letter. The choice to write a letter, and the time spent on it, illustrate how seriously this communicative act was taken.

The most interesting component of Hymes' SPEAKING model is perhaps the notion of instrumentalities, which stands for 'means or agencies of speaking' (Hymes 1986, 63 ) and it is used to avoid any explicit reference to a concept of language, although what is traditionally called language is definitely part of the instrumentalities of speaking (and of writing). Instrumentalities also comprise the medium and mode of communication and the semiotic resources of participants in general. Writing a letter requires the materials of a pen and a piece of paper (both of which were supplied by me), but it also calls for a particular set of linguistic resources in participants' repertoiresliteracy skills and $a$ language one can write in.

In describing people's repertoires of literacy and languaging, it is inevitable to refer to 'languages' as distinct ontological entities and name them by their commonly accepted names. Even if it is really languaging that is practiced, and if languages (in plural) are critically understood as 'inventions' (Makoni and Pennycook 2007) or effects of language policies (Shohamy 2006), pluralisable languages are still meaningful in the sense that people orient themselves in particular situations to languages as such (cf. Pietikäinen et al. 2008).

If we focus on the ethnolinguistic identities of the sender, mediator and receiver in the communication scheme (as is visually represented in Figure 4), we see that we are dealing with people from three different ethnic groups and three different generations. As a Fula in Foni, the old Ba-Abdoulie was fluent in both Mandinka and Fula. Since he had not been to school, he did not speak what he called tubaab kayo "white people's language' (either English or French) nor had he learned to write. The same holds for Lamin's mother who, unlike her four sons, but like her two daughters, had not been to school and had never learned to write either. As a Fula, she spoke Mandinka most of the time as she had married twice into Mandinka families. Since many of their neighbours are Jolas, Ba-Abdoulie and Lamin's mother spoke a considerable amount of Jola as well. Buba, the neighbour's boy, was a Jola, but spoke 


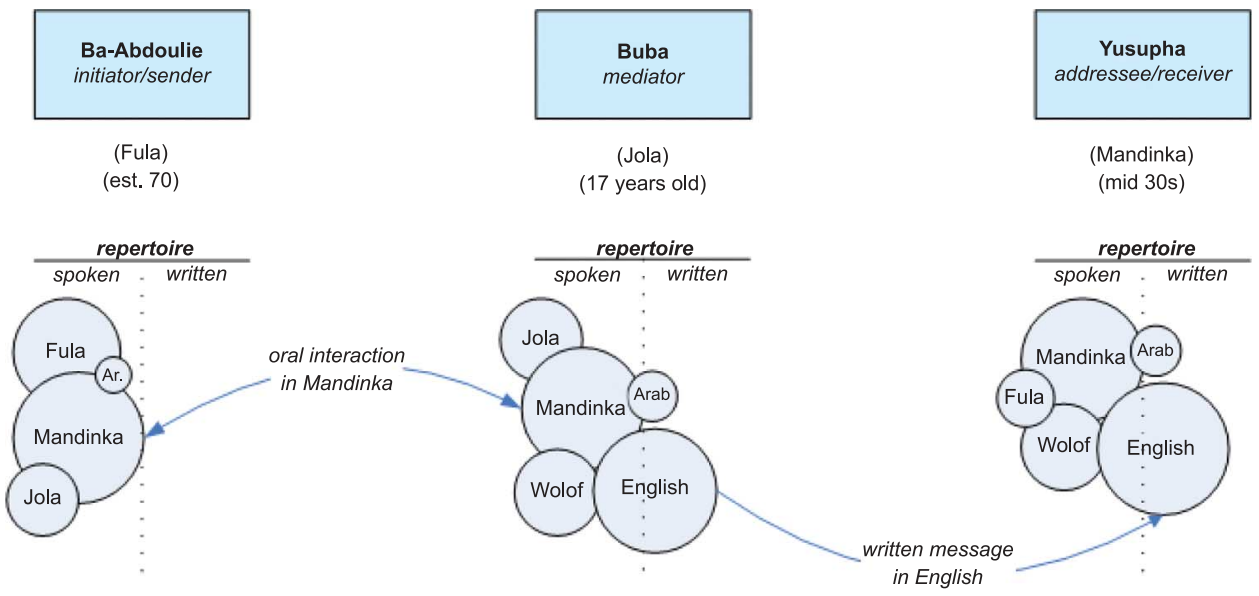

Figure 4. Mandinka and English in the repertoires of the participants.

Mandinka most often as this was the lingua franca of the village. He knew Jola as well and had, as a result of his education and residence in the urban areas, also learned to speak Wolof and English. The only language he had learned to write in, however, was English. Lamin's brother Yusupha was a Mandinka, and spoke Mandinka best and most often, but was, due to his work in a major hotel in Banjul, fluent in Wolof and English as well. He also understood his mother's Fula, but did not speak it as often as the other languages in his repertoire. Also for Yusupha, the only language he could read and write was English.

There was a common language in the repertoires of all the participants, i.e., Mandinka, but this language was not considered adequate for the task of writing the letter. The channel or medium of communication (speaking vs. handwriting) and the forms of speech (the languages Mandinka and English) are closely interconnected here. Mandinka was only spoken and English was written and read out (to be paraphrased in Mandinka again). The answer to the question why this letter was written in English, lies in the norms and genre conventions and expectations attached to letters and writing in general in Gambian society. Letter writing and ultimately literacy presupposes English (or Arabic) in this context. These norms and genre conventions have their source in the national school curriculum that uses only English for literacy instruction, as well as in the linguistic landscape which also presents an (almost) English-only environment. It becomes apparent here that public literacy regimes are reflected in private literacy products and practices. In the language repertoires of BaAbdoulie, Buba and Yusupha, English was the only language that lent itself to writing and not Mandinka, the commonly spoken language.

\section{Conclusions}

This article has opened with discerning an ongoing shift in the constitution of the object of sociolinguistics, i.e. a shift from a sociolinguistics that was defined as the study of who speaks (or writes) what language to whom, when and to what end (see Fishman 1972), to a sociolinguistics that is being defined as the study of who 
languages how and what is being languaged under particular circumstances in a particular place and time. It was argued that the notion of languaging as it has been proposed by various authors (Jørgensen 2008; Møller and Jørgensen 2009; Pietikäinen et al. 2008; Shohamy 2006) represents a key concept in this move away from studying languages as linguistic systems to studying language as a sociolinguistic system. The notion of languaging refocuses our attention on human beings that are engaged in particular activities (e.g., letter writing) and away from languages as things of their own. At the same time, the notion of languaging allows us to focus on the constraints in people's repertoires when practicing and producing language. It is thus possible to draw a few generalisations with regard to the local sociolinguistic system in Ba-Abdoulie's village on the basis of the micro-ethnographic case presented here.

Ba-Abdoulie's letter is first of all a typical moment of 'grassroots literacy', i.e., 'writing performed by people who are not fully inserted into elite economies of information, language and literacy' (Blommaert 2008, 7). Many characteristics of grassroots literacy (non-standardedness, draft-like quality, distant genres, rootedness in orality, etc.) are also pertinent here. One of the characteristics of literacy in peripheral places such as Ba-Abdoulie's village is that it is not 'ortho-graphic' but 'heterographic'. Orthographies are more or less powerful conventions prescribing how to write right. One of the 'consequences' of schooled literacy, to echo Goody and Watt (1963), is that it selects and fixes one variety of written language as the written language, i.e., the right, correct, or normative variety, and transmits the idea that all deviations from this norm are wrong, incorrect, abnormal. In heterographic situations, there is not one, but several prescriptive regimes on how to write right. In the absence of a single set of norms, individual and situational variation, like in spoken language, is not abnormalised but normal. Texts written in The Gambia (as in much of Africa) often reflect multiple orthographic traditions (see Juffermans 2009 for another example from Ba-Abdoulie's village).

In the case of Ba-Abdoulie's letter, we do not have the text itself at our disposal and can therefore not indicate where the text in question is heterographic, and how. We can, however, interpret the event to illustrate the 'exographic' nature of literacy in Ba-Abdoulie's village. 'Exographia' is a term used by Lüpke (2011) to refer to the situation in many of the world's smaller ethnolinguistic communities where writing exclusively takes place in another language. As is the case here, writing does not take place in Mandinka, Fula or Jola, the three languages in Ba-Abdoulie's community, but in English, a 'foreign' or non-native language to all of the participants in the literacy event. Languaging a letter in this local context involves English because that is the language in which written things are languaged. Local languaging here is not the sum of the local languages (Mandinka plus Jola plus Fula plus English) but is a complex repertoire in which different functions (e.g., speaking and writing) are distributed differently across different languages. Multilingualism here is truncated. There are certain things that are done with (features of) English that cannot be (or simply are not) done with other languages.

As a result of this unequal distribution of resources for languaging over the different languages and languagers, a literacy event such as Ba-Abdoulie's letter is inevitably a collaborative event. Local languaging here involves several persons in Ba-Abdoulie's network, each of whom bring along different linguistic resources to the communicative event. Ba-Abdoulie himself is equipped only with oral instrumentalities of speaking, which do not enable him to produce a letter autonomously. It is Buba, acting as mediator, who brings the instrumentalities of writing to the event. Local 
languaging is a collective, multilingual affair in this context, with an unequal distribution of the functions and instrumentalities in participants and in languages.

The old Ba-Abdoulie lived his sociolinguistic life in a local economy of literacy that is characterised by scarcity of all sorts of literacy resources, including literate expertise itself. Born in Guinea in the final decades of the French colonial empire, Ba-Abdoulie grew up entirely without formal, classroom-based education. As far as filling in forms, written correspondence and other more demanding literacy events are concerned, Ba-Abdoulie is fairly well functionally illiterate when literacy is regarded as 'a complex set of skills defined in terms of the print demands of occupational, civic, community and personal needs' (Verhoeven 1997, 128).

Within these material and educational constraints, a pen and a sheet of paper become valuable objects. These objects were not immediately in possession of either Buba or Ba-Abdoulie, but had to be borrowed from me. As a researcher, I was well equipped with these basic writing tools. But literate expertise is scarce as well in this context. The sort of skills Ba-Abdoulie needed to write his letter were not shared by members of his own generation, nor by members of his extended family present at that time. Here, writing was the result of intergenerational and interfamilial collaboration. Ba-Abdoulie was a respected elder and had the authoritative voice to formulate the request to his stepson Yusupha. Yet, he did not have the linguistic capital to express that request in the desired medium of the written word and in the language associated with that medium-English. Buba did not have that authoritative voice quite yet, nor was he a party in the nuptial negotiations, but he had the skills and knowledge to compose the message in the style and form of language that was required for a letter. Together, the old Ba-Abdoulie and the young Buba formed a successful couple and managed to language the letter. It is only with Buba's help that it became possible for Ba-Abdoulie to do literate things in his life, and to 'be literate' in a very restricted sense of the word.

As a result of the collaborative nature of literacy in this community, personal writing is not an exclusively private affair, but a rather public event. One of the characteristics of rural Gambian, perhaps rural African life in general, is that the more educated and literate family members very often leave their home village to work and/ or continue their education in the urban areas. Very few literate people stay behind in villages like that of Ba-Abdoulie. Consequently, there is not in every family at all times someone who can read and write, and in families where there is somebody like that, that person is often still school-going. As a result, literacy is a fairly communal affair, a collective good rather than a personal skill (cf. Papen 2005). Ba-Abdoulie could not ask any direct family members to help him with his letter, but had to appeal to a neighbour's boy. In this ecology of literacy, it is obvious that it is very hard to keep secrets or to solve family affairs in private circles. Everything appears to belong to the village here.

The letter writing event took place in September 2004 and that was the first and only time I have ever seen literacy (writing) take such a prominent place in the activities of people outside the walls of the school. This letter occupied Ba-Abdoulie, Buba, Lamin's mother (and myself) for a full afternoon. I have visited that same village and family a number of times since 2004 and have noticed a number of changes in their daily lives, one of which is the spread of mobile phones. I wonder if Ba-Abdoulie today (if he were still alive) would still find a letter the most appropriate genre to carry across this message. He might now just as well ask someone to lend him a mobile phone to have live contact with Yusupha. Mobile phones may be redrawing the sociolinguistic map of this part of the world, as it redistributes 
symbolic capital making certain groups of people less dependent on competences normally learned at school (such as classic literacy skills), but here too, the assistance of young members of the community is often needed to enable elderly persons to employ these new technologies.

The language of literacy in The Gambia is one language predominantly, not many. While The Gambia as a whole is distinctly multi-ethnic and multilingual and indeed many urban and rural communities and individuals are too, at the level of writing, this linguistic diversity is far less visible and involves only one or two 'languages': English and to a lesser extent also Arabic, but not local Gambian languages. Despite the education policy objectives adopted in 2004, that situation is not likely to change any time soon. Still, we may wonder what would happen with writing in local languages when the vast majority of young people have acquired confident literacy skills in English. Perhaps there will be an informal L2 to L1 transfer, and perhaps that will bring about important changes in Gambian literacy practices and society at large.

\section{Acknowledgements}

Fieldwork for this article was conducted in four periods between June 2004 and August 2005, with short return visits to the village in 2007 and 2008 during fieldwork in urban Gambia. Earlier versions of this article were presented at the Mediating Multilingualism Conference in Jyväskylä (June 2008) and the AILA World Congress in Essen (August 2008). I am grateful to Yonas Mesfun Asfaha, Danielle Boon, Abderrahman El Aissati, the editors of this issue and two anonymous reviewers for a comments, feedback and useful suggestions. Remaining shortcomings are my sole responsibility. The article is dedicated to the memory of Ba-Abdoulie, the old man in the title, who sadly passed away in January 2007.

\section{References}

Agar, M. 1995. Ethnography. In Handbook of pragmatics, ed. J. Verschueren, J.-O. Östman and J. Blommaert. Amsterdam, John Benjamins, 583-90.

Basso, K.H. 1974. The ethnography of writing. In: Explorations in the ethnography of speaking, ed. R. Bauman and J. Sherzer. Cambridge, Cambridge University Press, 425-32.

Bauman, R., and J. Sherzer. 1975. The ethnography of speaking. Annual Review of Anthropology, 4, 95-119.

Baynham, M. 2004. Ethnographies of literacy: Introduction. Language and Education 18, no. 4: 285-90.

Bell, A. 1997. Language style as audience design. In Sociolinguistics: A reader and coursebook, eds. N. Coupland and A. Jaworski. Basingstoke, Palgrave, 240-50.

Blommaert, J. 2005. Discourse: A critical introduction. Cambridge: Cambridge University Press.

Blommaert, J. 2008. Grassroots literacy: Writing, identity and voice in central Africa. London: Routledge.

Blommaert, J., J. Collins and S. Slembrouck 2005. Spaces of multilingualism. Language \& Communication 25, 197-216.

Council of Europe. 1996. Common European framework of reference for languages: Learning, teaching, assessment. Cambridge: Cambridge University Press.

Dyers, C. 2008. Truncated multilingualism or language shift? An examination of language use in intimate domains in a new non-racial working class township in South Africa. Journal of Multilingual and Multicultural Development 29, no. 2: 110-26.

Fabian, J., ed. 1990. History from below: The 'vocabulary of Elisabethville' by André Yav: Text, translations, and interpretive essay. Amsterdam: John Benjamins.

Fishman, J.A. 1972. The relationship between micro- and macro-sociolinguistics in the study of who speaks what language to whom and when. In Sociolinguistics: Selected readings, eds. J.B. Pride and J. Holmes. London, Penguin Books, 15-32. 
Gafaranga, J. 2000. Language separateness: A normative framework in studies of language alternation. Estudios de Sociolingüística 1, no. 1: 65-84.

Gee, J. P. 1996. Social linguistics and literacies: Ideology in discourses. London: Taylor \& Francis.

Geertz, C. 1973. Thick description: Toward an interpretive theory of culture. The interpretation of cultures: Selected essays. New York: Basic Books, 3-30.

Goody, J., and I. Watt. 1963. The consequences of literacy. Comparative Studies in Society and History 5, no. 3: 304-45.

Hymes, D.H. 1967. Models of the interaction of language and social setting. Journal of Social Issues 2, 8-28.

Hymes, D.H. 1986. Models of the interaction of language and social life. In Directions in sociolinguistics: The ethnography of communication, eds. J.J. Gumperz and D.H. Hymes. Oxford: Blackwell, 35-71.

Jacquemet, Marco. 2005. Transidiomatic practices: Language and power in the age of globalization. Language \& Communication 25, 257-77.

Jakobson, R. 1960. Closing statement: Linguistics and poetics. In Style in language, ed. T.A. Sebeok. Cambridge: MIT Press, 350-77.

Jørgensen, J. Normann. 2008. Polylingual languaging around and among children and adolescents. International Journal of Multilingualism 5, no. 3: 161-76.

Joseph, J. E. 2002. Is language a verb? Conceptual change in linguistics and language Teaching. In Language in language teacher education, eds. H.R. Trappes-Lomax and G. Ferguson. Amsterdam: John Benjamins, 29-47.

Juffermans, K. 2009. How to write if you cannot write: Collaborative literacy in a Gambian village. In I. Van De Craats and J. Kurvers. Eds. Low-educated adult second language and literacy acquisition: Proceedings of the 4th symposium, Antwerp 2008. Utrecht, LOT, 223-34.

Kroon, S., and J. Sturm 2000. Comparative case study research in education: Methodological issues in an empirical-interpretive perspective. Zeitschrift für Erziehungswissenschaft 3, no. 4: 559-76.

Lawson, S., and A. Jaworski. 2007. Shopping and chatting: Reports of tourist-host interaction in the Gambia. Multilingua 26, no. 1: 67-93.

Lüpke, F. 2011. Orthography development. In Handbook of endangered languages, eds. P. Austin and J. Sallabank. Cambridge: Cambridge University Press.

Makoni, S., and A. Pennycook. 2007. Disinventing and reconstituting languages. In: Disinventing and reconstituting languages, eds. S. Makoni and A. Pennycook. Clevedon: Multilingual Matters, 1-41.

Mbodj-Pouye, A. 2009. Tenir un cahier dans la région cotonnière du mali: Support d'écriture et rapport à soi. Annales. Histoire, Sciences sociales 64, no. 4: 855-86.

Mignolo, W.D. 1996. Linguistic maps, literary geographies, and cultural landscapes: Languages, languaging, and (trans)nationalism. Modern Language Quarterly 57, no. 2: 181-96.

Møller, J.S., and Jørgensen, J. Normann. 2009. From language to languaging: Changing relations between humans and linguistic features. Acta Linguistica Hafniensia 41: 143-66.

Papen, U. 2005. Adult literacy as social practice: More than skills. London: Routledge.

Pietikäinen, Sari, Alanen, Riika, Dufva, Hannele, Kalaja, Paula, Leppänen, Sirpa, and Pitkänen-Huhta, Anne. 2008. Languaging in ultima thule: Multilingualism in the life of a sami boy. International Journal of Multilingualism 5, no. 2: 79-99.

Rampton, B. 1995. Crossing: Language and ethnicity among adolescents. London: Longman.

Rampton, B., K. Tusting, J. Maybin, R. Barwell, A. Creese, and V. Lytra. 2004. UK linguistic ethnography: A discussion paper. UK Linguistic Ethnography Forum: www.lingethnog.org.uk.

Shohamy, E. 2006. Language policy: Hidden agendas and new approaches. London: Routledge.

Street, B.V. 1995. Social literacies: Critical approaches to literacy in development, ethnography and education. London: Longman.

Street, B.V. 2000. Literacy events and literacy practices: Theory and practice in new literacy studies. In Multilingual literacies: Reading and writing in different worlds, eds. M. Martin-Jones and K.E. Jones. Amsterdam: John Benjamins, 17-29. 
Swigart, L. 1992. Two codes or one? The insiders' view and the description of codeswitching in Dakar. Journal of Multilingual and Multicultural Development 13, nos. 1-2: 83-102.

Thorne, S. L., and J.P. Lantolf. 2007. A linguistics of communicative activity. In Disinventing and reconstituting languages, eds. S. Makoni and A. Pennycook. Clevedon, Multilingual Matters, 170-95.

Verhoeven, L. 1997. Functional literacy. In Encyclopedia of language and education, eds. V. Edwards and D. Corson. Volume 2: Literacy. Dordrecht, Kluwer, 127-32.

Vološ inov, Valentin N. 1986. Marxism and the philosophy of language. Cambridge: Harvard University Press.

Willis, P., and M. Trondman. 2000. Manifesto for ethnography. Ethnography 1, no. 1: 5-16. 